\title{
Fake Food
}

\section{Erhard Taverna}

Dr. med., Mitglied der Redaktion

Erst kommt das Fressen und dann die Moral, schrieb Brecht in seiner Dreigroschenoper. Ohne Brot keine Spiele. In pharaonischen Gräbern findet man Miniaturbäckereien für die Toten im Jenseits. Immer wieder führten Naturkatastrophen und Kriege zu Ernährungskrisen und Hungersnöten. Im Kriegsjahr 1914 gab es in Deutschland eine Anstecknadel «Das letzte Kipfel», aus dem Verzicht wurde eine Heldentat. Doch Not macht auch erfinderisch. Es gibt viele Beispiele für

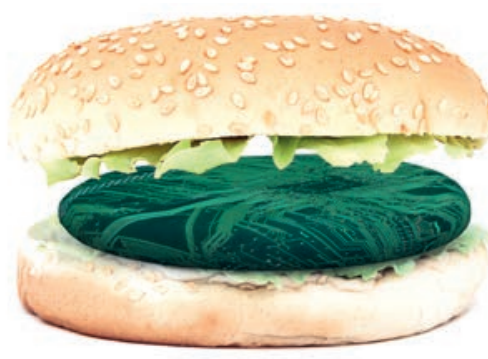

Sandwich mit elektronischem Burger, synthetisches Fleischkonzept, Illustration 3-D. Streck- und Ersatzstoffe. Etwa Zichorienkaffee aus den Wurzeln des Löwenzahns oder Muckefuck, ein Wort aus Mocca faux für falschen Kaffee. Die Kontinentalsperre zu Zeiten Napoleons förderte den Erfindergeist. Margarine als Butterersatz steigerte die Schlagkraft des Militärs, die Züchtung ertragreicher $\mathrm{Zu}$ ckerrüben und der forcierte Anbau brachten den Kunsthonig und machten die Kontinentalmächte vom englischen Rohrzucker unabhängig. Der Kartoffelanbau, obrigkeitlich durchgesetzt, befreite Preussen von Getreideeinfuhren. Was wir essen oder nicht essen, hat strategische Bedeutung. Aus Abfallprodukten der $\mathrm{Zu}$ ckergewinnung entsteht Bagasse; die ausgepresste Pflanzensubstanz ist ein vielseitiger Rohstoff. Gefördert durch die Kriegswirtschaft, werden daraus seit 1939 Papier und Zellstoff gewonnen. Ingenieure fertigen aus

\section{Erst kommt das Fressen und dann die Moral, schrieb Brecht in seiner Dreigroschenoper.}

dem Futtermittel Spanplatten und Sitzmöbel. Aus einem weiteren Nebenprodukt, der Melasse, entstand die Rumfabrikation. Sie sicherte England eine dreihundertjährige Seeherrschaft, denn jeder britische Seemann erhielt an Bord zweimal täglich eine Gratisportion Rum. Durch Pyrolyse von Melasse und weitere chemische Aufspaltungen entsteht Blausäure, die über die Bekämpfung von Schädlingen, als Zyklon $\mathrm{B}$, eine fürchterliche Bekanntheit erlangte. Heute ist die Melasse der wichtigste Rohstoff bei der Herstellung von Backhefe.

Geniale Tüftler und viel Chemie sichern die Ernährung und den täglichen Komfort. Alfred Döblin, bekannt durch Berlin Alexanderplatz, schrieb auch einen $\mathrm{Zu}$ kunftsroman, Berge Meere und Giganten, der 1924 er- eine künstliche Lebensmittelsynthese nachdachten. «Sie hatten sich längst an die künstlichen, sehr raffiniert aufgemachten Stoffe gewöhnt, die in jedem Überfluss zu jeder Zeit vorhanden waren [...] Es wäre den Menschen, die schon in dritter und vierter Generation künstliche Nahrung zu sich nahmen, schwer geworden, zur natürli-

\section{Fleisch schneidet bei einer Klimabilanz} schlecht ab, Alternativen mit Soja oder Palmöl aus Übersee sind nicht viel besser.

chen Kost zurückzukehren [...] Es trat ein beispielloser allgemeiner Umschwung ein. Es erfolgte eine Veränderung aller Lebensverhältnisse, zugleich die Nötigung zu strengen, ja strengsten Herrschaftsformen zurückzukehren.» Was Döblin in das 26. Jahrhundert verlegt, scheint heute in greifbarer Reichweite. Das beginnt schon damit, dass viele Vegetarier und Veganer auf den Geschmack von Fleisch oder Milch und Eiern nicht verzichten wollen. Der Beyond Meat Burger ist angekommen. Ein Produkt aus Erbseneiweiss, Bambuszellulose, Kartoffelstärke, Gummi arabicum, Rapsöl, Ascorbinsäure und Randensaft - Emulgatoren, Geschmacksverstärker, Stabilisatoren und die ganze E-Liste inbegriffen. Man wolle die Welt zu einem besseren Ort machen, steht auf der Website von Beyond Meat, dem Unternehmen, das jüngst an die Börse ging. Wurst ohne Fleisch ist ein Massengeschäft. Dank Enzymtechnik florieren Imitate aus Tofu, Quorn, Tempeh, Seitan oder Lupinenbohnen. Seitan, gewonnen aus Weizeneiweissfasern, sorgt für die gewohnte Fleischkonsistenz. Das Geheimnis der richtigen Rezeptur besteht im Würzen und in der Mischung zahlreicher Zusatzstoffe, die bei der Produktion von Ersatzmilch und -käse hochtechnisierte Herstellungsketten durchlaufen.

Fleisch schneidet bei einer Klimabilanz schlecht ab, Alternativen mit Soja oder Palmöl aus Übersee sind nicht viel besser. Der Chemiebaukasten hat seine Tücken. Eine vegetarische Currywurst ist kalorienreicher als das Original.

Gut ist es, aus regionalen Produkten und saisongerecht selber zu kochen. Doch vielleicht ist Fake Food die Zukunft einer acker- und sonnenlosen Lebensmittelproduktion, für eine überbevölkerte Erde. Wir sind auf bestem Wege.

Bildnachweis

(c) Fabio Berti | Dreamstime.com 